\title{
Mixed Silica Titania Materials Prepared from a Single-Source Sol-Gel Precursor: A Time-Resolved SAXS Study of the Gelation, Aging, Supercritical Drying, and Calcination Processes
}

\author{
Viktoria Torma,${ }^{\dagger}$ Herwig Peterlik, ${ }^{\dagger}$ Ulrike Bauer, ${ }^{\dagger}$ Wolfgang Rupp,${ }^{\dagger}$ Nicola Hüsing, ${ }^{\dagger}$ \\ Sigrid Bernstorff, ${ }^{\S}$ Milos Steinhart, ${ }^{\S}$ Günter Goerigk," and Ulrich Schubert*, ${ }^{*}$ \\ Institute of Materials Chemistry, Vienna University of Technology, Getreidemarkt 9, A-1060 Wien, Austria, \\ Institute of Materials Physics, University of Vienna, Boltzmanngasse 5, A-1090 Wien, Austria, Sincrotrone \\ Trieste S.C.p.A., Strada Statale 14, I-34012 Trieste, Italy, and Institut für Festkörperforschung, \\ Forschungszentrum Jülich, D-52425 Jülich, Germany
}

Received November 15, 2004. Revised Manuscript Received April 15, 2005

\begin{abstract}
The morphology of gels prepared from a silica/titania single-source precursor (1), obtained by reaction of 3-oxoethyl-6-trimethoxysilyl-hexan-2-one with $\mathrm{Ti}\left(\mathrm{O}^{\mathrm{i} P r}\right)_{4}$, was investigated by small-angle X-ray scattering (SAXS) through all stages of the preparation process, that is, gelation, aging, drying, and calcination. The same investigations were performed for mixtures of $\mathbf{1}$ and $\mathrm{Si}(\mathrm{OEt})_{4}$. Immediately after the start of the reaction small primary particles are formed, the size of which $(r=0.5 \pm 0.1 \mathrm{~nm})$ remains constant through the gelation and aging process. Anomalous small-angle X-ray scattering (ASAXS) measurements strongly indicate that the primary particles are formed by hydrolysis and condensation of the titanium alkoxide moiety of $\mathbf{1}$. Condensation proceeds by a slower aggregation of the primary particles. Additional $\mathrm{Si} / \mathrm{O}$ from $\mathrm{Si}(\mathrm{OEt})_{4}$ is incorporated between the clusters. The size of the mass fractal secondary particles formed by aggregation of the primary particles increases approximately exponentially with the time. Drying by either solvent evaporation or supercritical extraction with $\mathrm{CO}_{2}$ results in a decrease of the primary particle size to $r=0.4 \mathrm{~nm}$, and the secondary particles also become smaller. The primary particles disappear during calcination in air, that is, when the organic groups tethering the silicon and titanium atoms are destroyed. However, the general structure of the network is maintained.
\end{abstract}

\section{Introduction}

An inherent problem in the preparation of mixed oxides by hydrolytic sol-gel processing of a precursor mixture is that phase separation may occur because of the different hydrolysis and condensation rates of the individual compounds. Approaches to avoid at least macroscopic phase separation are (i) the prehydrolysis of the slower reacting component, (ii) the lowering of the reactivity of the faster reacting precursor by chemical modifications, viz. by replacing part of the alkoxide groups by chelating or bridging multidentate ligands, or (iii) the use of single-source precursors. ${ }^{1}$

We have recently shown that single-source precursors with an organic spacer between silicon and transition metal alkoxide moieties can be prepared by reaction of 3-oxoethyl6-trimethoxysilyl-hexan-2-one $(\mathrm{OTH}-\mathrm{H})$ with metal alkoxides. ${ }^{2,3} \mathrm{OTH}-\mathrm{H}$ contains a $\beta$-diketonate moiety and is thus able to react with transition metal alkoxides by substitution

* To whom correspondence should be addressed. E-mail: uschuber@ mail.zserv.tuwien.ac.at.

$\dagger$ Vienna University of Technolog.

¥University of Vienna.

$\S$ Sincrotrone Trieste S.C.p.a.

"Forschungszentrum Jülich.

(1) For example: Holland, M. A.; Pickup, D. M.; Mountjoy, G.; Tsang, E. S. C.; Wallidge, G. W.; Newport, R. J.; Smith, M. E. J. Mater. Chem. 2000, 10, 2495. Yoldas, B. E. J. Non-Cryst. Solids 1980, 38, 81.

(2) Rupp, W.; Hüsing, N.; Schubert, U. J. Mater. Chem. 2002, 12, 2594.

(3) Puchberger, M.; Rupp, W.; Bauer, U.; Schubert, U. New J. Chem. 2004, 28, 1289 . of one or more alkoxo ligands. The precursor ( $\left.{ }^{\mathrm{P} r O}\right)_{3} \mathrm{Ti}(\mathrm{OTH})$ (1) obtained by the reaction of $\mathrm{OTH}-\mathrm{H}$ with $\mathrm{Ti}\left(\mathrm{O}^{\mathrm{i}} \mathrm{Pr}\right)_{4}(\mathrm{eq}$ 1) allowed for the preparation of homogeneous, transparent gels by hydrolysis and condensation reactions, i.e., by solgel processing. After removal of the organic groups by calcination, silica-titania mixed oxide powders were obtained which were $\mathrm{X}$-ray amorphous up to a calcination temperature of $700{ }^{\circ} \mathrm{C}$ (for $\mathrm{OTH}-\mathrm{H}$ : $\mathrm{Ti}\left(\mathrm{O}^{\mathrm{i} P r}\right)_{4}=1$ ). Above calcination temperatures of $800{ }^{\circ} \mathrm{C}$, anatase nanocrystals $(7$ $\mathrm{nm}$ at $900{ }^{\circ} \mathrm{C}$, increasing to $21 \mathrm{~nm}$ at $1100{ }^{\circ} \mathrm{C}$ ) started to develop, and the anatase-rutile transformation took place above $1000{ }^{\circ} \mathrm{C} .^{2}$ In passing it should be noted that the structure of 1 shown in eq 1 is simplified because $\mathrm{Ti}(\mathrm{OR})_{3^{-}}$

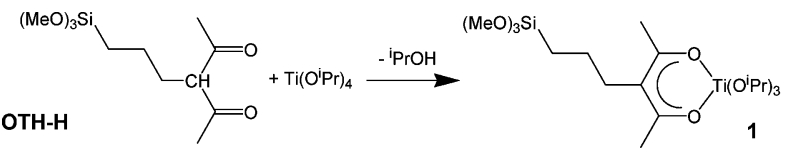

( $\beta$-diketonate) derivatives are dimeric in the solid state, ${ }^{4}$ and monomer-dimer equilibria exist in solution. ${ }^{5}$

In the gels obtained from $\mathbf{1}$, macroscopic phase separation cannot occur owing to the chemical link between the different alkoxide moieties. Clusters with a $\mathrm{Si} / \mathrm{O}$ or $\mathrm{Ti} / \mathrm{O}$ core could nevertheless be formed if either the $\mathrm{Si}(\mathrm{OR})_{3}$ or the $\mathrm{Ti}(\mathrm{OR})_{3}$

(4) Errington, R. J.; Ridland, J.; Clegg, W.; Coxall, R. A.; Sherwood, J. M. Polyhedron 1998, 17, 659.

(5) Léaustic, A.; Babonneau, F.; Livage, J. Chem. Mater. 1989, 1, 240 


\section{Scheme 1. Processing Map and Numbering Scheme of the Investigated Samples \\ Sol-gel processing of 1 and (optionally) TEOS}

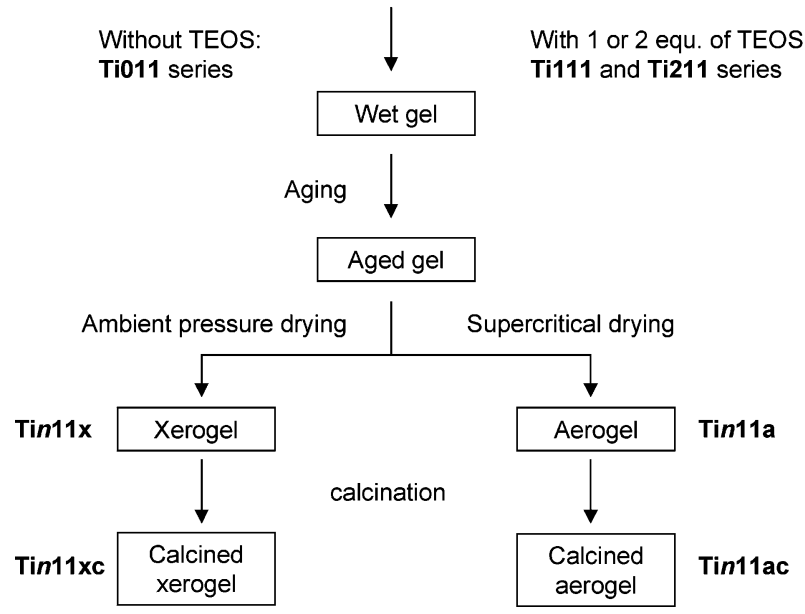

moiety is preferentially hydrolyzed. The starting situation is similar to that of $(\mathrm{EtO})_{3} \mathrm{Si}-\mathrm{O}-\mathrm{Al}(\mathrm{OBu})_{2}$ as a precursor for aluminosilicate gels, where such a behavior was observed. ${ }^{6}$ An important difference between 1 and the $\mathrm{Si} / \mathrm{Al}$ precursor is, however, that redistribution reactions (giving $\mathrm{Si}-\mathrm{O}-\mathrm{Si}$ and $\mathrm{Al}-\mathrm{O}-\mathrm{Al}$ bonds) are not possible; i.e., precursors with an organic spacer between the two alkoxide moieties should be more robust during sol-gel processing.

In the present work, the morphology of gels prepared from 1 was investigated by small-angle X-ray scattering (SAXS) through all stages of the preparation process, that is, gelation, aging, drying, and calcination. The same investigations were performed for systems where mixtures of $\mathbf{1}$ and $\mathrm{Si}(\mathrm{OEt})_{4}$ (TEOS) were co-processed. The processing map is shown in Scheme 1.

The gels are designed as $\mathbf{T i n} \mathbf{1 1}$, where $n$ represents the molar equivalents of TEOS $(n=0-2)$ and " 11 " the Ti:OTH molar ratio of 1:1. Thus, the sample Ti111 was prepared from TEOS, $\mathrm{Ti}\left(\mathrm{O}^{\mathrm{i}} \mathrm{Pr}\right)_{4}$, and $\mathrm{OTH}-\mathrm{H}$ in 1:1:1 molar ratio, as an example. The gels obtained by sol-gel processing of $\mathbf{1}$ in the absence of TEOS are designed as Ti011. The letter $\mathbf{x}$ after the numbers refers to xerogels, the letter a to aerogels, and the letter $\mathbf{c}$ to calcined samples. For example, Ti011ac is a calcined aerogel obtained from the wet gel Ti011.

Although SAXS cannot provide unambiguous structural information on the network formed, the method nevertheless allows important information to be gained on the key features of the network morphology, that is, the diameter of primary and secondary particles formed during sol-gel processing, as well as the fractal dimension. ${ }^{7,8}$ Schaefer et al. have shown that the scattering profile of gels obtained from arylenebridged alkoxysilanes $(\mathrm{EtO})_{3} \mathrm{Si}\left(\mathrm{C}_{6} \mathrm{H}_{4}\right)_{n} \mathrm{Si}(\mathrm{OEt})_{3}(n=1-3)$ was similar to that prepared from $\mathrm{Si}(\mathrm{OR})_{4} \cdot{ }^{9}$ Thus, the morphology is not qualitatively changed by the bridging

(6) Pouxviel, J. C.; Boilot, J. P.; Lecomte, A.; Dauger, A. J. Phys. 1987, 48, 921. Pouxviel, J. C.; Boilot, J. P.; Dauger, A.; Wright, A. J. NonCryst. Solids 1988, 103, 331.

(7) Teixeira, J. J. Appl. Crystallogr. 1988, 21, 781

(8) Freltoft, T.; Kjems, J. K.; Sinha, S. K. Phys. Rev. B 1986, 33, 269.

(9) Schaefer, D. W.; Beaucage, G.; Loy, D. A.; Shea, K. J.; Lin, J. S. Chem. Mater. 2004, 16, 1402 organic groups which are integrated in the network. However, the case of 1 is different from that of $(\mathrm{RO})_{3} \mathrm{Si}-\mathrm{X}-\mathrm{Si}(\mathrm{OR})_{3}$ precursors because two different metal alkoxide moieties are involved.

\section{Experimental Section}

Materials. OTH $-\mathrm{H}$ was synthesized as described previously. ${ }^{3}$ Methanol was dried over magnesium.

Hydrolysis Experiments on $\mathrm{Ti}\left(\mathrm{O}^{\mathrm{iPr}}\right)_{3}(\mathrm{acac}) / \mathrm{PrSi}(\mathrm{OMe})_{3} \mathrm{Mix}-$ tures. An amount of $1.04 \mathrm{~g}$ (3.65 mmol) of $\mathrm{Ti}\left(\mathrm{O}^{\mathrm{i} P r}\right)_{4}$ was mixed with $0.365 \mathrm{~g}$ (3.65 mmol) of acetylacetone and stirred for $30 \mathrm{~min}$ in an atmosphere of dry argon. After addition of $0.62 \mathrm{~g}(3.65 \mathrm{mmol})$ of propyltrimethoxysilane, the yellow mixture was diluted with 2.53 $\mathrm{mL}(62.4 \mathrm{mmol})$ of methanol. Further reactions were performed at ambient atmosphere. After dropwise addition of $0.4 \mathrm{~mL}(22 \mathrm{mmol})$ of a $0.01 \mathrm{M} \mathrm{NH}_{4} \mathrm{OH}$ solution, the mixture was stirred for $5 \mathrm{~min}$ and aged at $30{ }^{\circ} \mathrm{C}$ for 7 days in a closed bottle and then submitted to SAXS measurements.

Preparation of Wet Gels from 1. $\mathrm{Ti}\left(\mathrm{O}^{i} \mathrm{Pr}\right)_{4}$ was mixed with 1 $\mathrm{M}$ equivalent of $\mathrm{OTH}-\mathrm{H}$ and stirred for $30 \mathrm{~min}$ in an atmosphere of dry argon. After addition of the required amount of TEOS, the yellow solution was diluted with methanol. Further reactions were performed in an ambient atmosphere. After addition of $0.01 \mathrm{M}$ $\mathrm{NH}_{4} \mathrm{OH}$ solution and stirring for 5 min, a small part of the reaction mixture was transferred to a quartz capillary using a syringe, and the SAXS measurements were immediately started. The remaining part of the solution was gelled and aged at $30{ }^{\circ} \mathrm{C}$ for 7 days in closed bottles and used for further measurements. The composition of the starting mixtures is given in Table 1.

Drying. Drying at ambient conditions-to produce xerogelswas carried out by removing the cover of the bottles of the aged gels and allowing the volatile components to evaporate within $3 \mathrm{~d}$.

Supercritical drying was performed as previously described. ${ }^{18}$ The mother solvent (mainly methanol) of the gels was exchanged to liquid $\mathrm{CO}_{2}$, followed by the continuous increasing of pressure and temperature until the solvent reached the supercritical state (about 74 bar and $31{ }^{\circ} \mathrm{C}$ ). Slow depressurizing produced the aerogels.

Calcination. The dried xerogel and aerogel monoliths were heated at the rate of $5{ }^{\circ} \mathrm{C} / \mathrm{min}$ in air until a temperature of $450{ }^{\circ} \mathrm{C}$ was reached, and then they were held at $450{ }^{\circ} \mathrm{C}$ for $30 \mathrm{~min}$. Heating for a longer period did not result in further structural changes.

SAXS Measurements. The time-resolved SAXS curves were recorded every $30 \mathrm{~s}$, which resulted in scattering intensities $I(q)$ vs scattering vector $q=4 \pi / \lambda \cdot \sin (\theta)$, with $2 \theta$ being the scattering angle between the incident and the diffracted beam. Quartz capillaries with $2 \mathrm{~mm}$ diameter and $0.01 \mathrm{~mm}$ wall thickness were used as sample holders. The experiments were started immediately after inserting the capillary filled with the reaction mixture into the beam, which was about 2 min after addition of water (at $t=0)$. The energy

(10) Haubold, H.-G.; Gruenehagen. K.; Wagener, M.; Jungbluth, H.; Heer, H.; Pfeil, A.; Rongen, H.; Brandenburg, G.; Moeller, R.; Matzerath, J.; Hiller, P.; Halling, H. Rev. Sci. Instrum. 1989, 60, 1943.

(11) Amenitsch, H.; Bernstorff, S.; Rappolt, M.; Kriechbaum, M.; Mio, H.; Laggner, P. J. Synchrotron Rad. 1998, 5, 506.

(12) Porod, G. Kolloid Z. 1952, 125, 51

(13) Emmerling, A.; Perticevic, R.; Beck, A.; Wang, P.; Sheller, H.; Fricke, J. J. Non-Cryst. Solids 1995, 185, 240.

(14) Krakovsky, I.; Urakawa, H.; Kajiwara, K.; Kohjira, S. J. Non-Cryst. Solids 1998, 231, 31.

(15) Meakin, P. J. Sol-Gel Sci. Technol. 1999, 15, 97

(16) Gerber, T.; Himmel, B. J. Phys. IV 1993, 3 (C8), 385

(17) Mrowiec-Białon, J.; Pajak, L.; Jarzebski, A. B.; Lachowski, A. I. Malinowski, J. J. J. Non-Cryst. Solids 1998, 225, 115.

(18) Hüsing, N.; Schubert, U.; Misof, K.; Fratzl, P. Chem. Mater. 1998 10,3024 . 
Table 1. Composition of the Starting Mixtures

\begin{tabular}{|c|c|c|c|c|c|}
\hline $\begin{array}{c}\text { composition } \\
\text { TEOS:Ti( }\left(\mathrm{O}^{i} \mathrm{Pr}\right)_{4}: \mathrm{OTH}-\mathrm{H}\end{array}$ & TEOS $[\mathrm{mL}]$ & $\operatorname{Ti}\left(\mathrm{O}^{i} \operatorname{Pr}\right)_{4}[\mathrm{~g}]$ & $\mathrm{OTH}-\mathrm{H}[\mathrm{g}]$ & $\mathrm{MeOH}[\mathrm{mL}]$ & $\mathrm{H}_{2} \mathrm{O}[\mathrm{mL}]$ \\
\hline $0: 1: 1$ & & $\begin{array}{c}1.04 \\
(3.65 \mathrm{mmol})\end{array}$ & $\begin{array}{c}0.968 \\
(3.65 \mathrm{mmol})\end{array}$ & $\begin{array}{c}2.53 \\
(62 \mathrm{mmol})\end{array}$ & $\begin{array}{c}0.4 \\
(22 \mathrm{mmol})\end{array}$ \\
\hline $1: 1: 1$ & $\begin{array}{c}0.814 \\
(3.65 \mathrm{mmol})\end{array}$ & $\begin{array}{c}1.04 \\
(3.65 \mathrm{mmol})\end{array}$ & $\begin{array}{c}0.968 \\
(3.65 \mathrm{mmol})\end{array}$ & $\begin{array}{c}3.80 \\
(104 \mathrm{mmol})\end{array}$ & $\begin{array}{c}0.53 \\
(29 \mathrm{mmol})\end{array}$ \\
\hline $2: 1: 1$ & $\begin{array}{c}1.627 \\
(7.3 \mathrm{mmol})\end{array}$ & $\begin{array}{c}1.04 \\
(3.65 \mathrm{mmol})\end{array}$ & $\begin{array}{c}0.968 \\
(3.65 \mathrm{mmol})\end{array}$ & $\begin{array}{c}5.06 \\
(124 \mathrm{mmol})\end{array}$ & $\begin{array}{c}0.66 \\
(37 \mathrm{mmol})\end{array}$ \\
\hline
\end{tabular}

of the beam was $8 \mathrm{keV}$, which corresponds to a X-ray wavelength of $\lambda=0.154 \mathrm{~nm}$. All experiments, except the in situ calcination experiment, were performed at room temperature.

For the aging experiments, a laboratory X-ray source (rotating anode) equipped with a 2D position-sensitive X-ray detector was sufficient. For the experiments, which required a higher time resolution, different synchrotron radiation sources were used: The gelation process of Ti011 was measured at the JUSIFA ${ }^{10}$ beamline at HASYLAB, Hamburg, with a two-dimensional position-sensitive detector. Two different sample-detector distances were used to cover a wide range of the scattering vector: The high $q$-region $\left(0.2-5.5 \mathrm{~nm}^{-1}\right)$ was recorded in a short configuration with a sample-detector distance of $0.935 \mathrm{~m}$ and the small- $q$-region $\left(0.05-1.4 \mathrm{~nm}^{-1}\right)$ in a long configuration with a detector-sample distance of $3.635 \mathrm{~m}$.

The gelation of Ti111 and Ti211, the solvent exchange, supercritical drying, and calcination experiments were carried out at the SAXS beamline ${ }^{11}$ of the synchrotron ELETTRA, Trieste. Again, two different sample-detector distances were used: $75 \mathrm{~cm}$ (at $8 \mathrm{keV}$ photon energy) to cover a range of $q$-values from 0.1 to $2 \mathrm{~nm}^{-1}$ and $2.25 \mathrm{~m} \mathrm{(at} 16 \mathrm{keV}$ ) for a range of 2 to $8 \mathrm{~nm}^{-1}$. The SAXS data were recorded with a linear detector. An additional WAXS detector enabled the simultaneous determination of the scattering intensity in a $q$-range from 8 to $15 \mathrm{~nm}^{-1}$. The BW4 beamline at HASYLAB, Hamburg, offered the possibility of USAXS measurements in the small $q$-range toward $0.02 \mathrm{~nm}^{-1}$. The recording time for the scans was 5 min.

ASAXS Measurements. Anomalous small-angle X-ray scattering (ASAXS) measurements on the wet gel and aerogel Ti011 were performed at the JUSIFA beamline at HASYLAB, Hamburg. The samples were kept in a vacuum to minimize the absorption and the background scattering caused by air. The scans were recorded for $2 \mathrm{~h}$ in the case of the wet gels and $40 \mathrm{~min}$ in the case of the aerogels on both of the used beam energies (4933 and $4983 \mathrm{eV}$ ) and for each distance $(0.535 \mathrm{~m}$ using a special sample holder, and $3.635 \mathrm{~m}$, respectively). The wet gels were aged 1 month before the SAXS experiments to prevent artifacts from any influence of an ongoing aging processes. The wet gel samples were packed in a thin polyethylene foil to avoid drying during the measurements, and the aerogels were pulverized and mounted on transparent adhesive tape.

Evaluation of SAXS Data. To describe the development of the network quantitatively, the approach from Freltoft et al. ${ }^{8}$ is used. The scattering intensity from a system composed of aggregates of primary particles can be expressed by

$$
I(q)=A \cdot P(q) \cdot S(q)
$$

where $A$ is a parameter depending on the total volume of the primary particles, $P(q)$ is the form factor, and $S(q)$ the structure factor. ${ }^{12}$ For the form factor, the Debye function is used for simplicity. This function correctly describes the form factor of spheres with the radius $r$ in the limiting case toward high values of $q .{ }^{13}$

$$
P(q)=\frac{1}{\left(1+\sqrt{2} q^{2} r^{2} / 3\right)^{2}}
$$

To obtain an analytical expression for the structure factor for clusters of particles with fractal dimension $D$, a cutoff parameter $\xi$ was introduced ${ }^{7,8}$ to describe the limited size of the clusters. The structure factor is then directly obtained by the Fourier transform, ${ }^{14}$

$$
S(q)=1+\frac{C \cdot \Gamma(D-1) \cdot \xi^{D} \cdot \sin ((D-1) \cdot \arctan (q \xi))}{\left(1+q^{2} \xi^{2}\right)^{(D-1) / 2} \cdot q \xi}
$$

As can be seen from the limiting behavior of $S(q)$ at $q=0, B+$ 1 represents an average number of primary particles per aggregate, with $B=C \cdot \Gamma(D-1) \cdot \xi D .{ }^{14}$ The parameter $\xi$ is connected with the radius of gyration of the secondary particles, with $R_{G}=\xi(D(D+$ 1)/2) $0.5 \cdot 7,15$

\section{Results}

Hydrolysis of a $\mathrm{Ti}\left(\mathrm{O}^{\mathrm{i}} \mathrm{Pr}\right)_{3}(\mathrm{acac}) / \mathrm{PrSi}(\mathrm{OMe})_{3}$ Mixture. For comparison with the gelation behavior of $\mathbf{1}$, an equimolar mixture of (acac) $\mathrm{Ti}\left(\mathrm{O}^{\mathrm{i}} \mathrm{Pr}\right)_{3}$, prepared in situ from $\mathrm{Ti}\left(\mathrm{O}^{\mathrm{i}} \mathrm{Pr}\right)_{4}$ and acetylacetone (acac-H), and (propyl)Si(OMe) $)_{3}$ was reacted with water under the same conditions. The electronic effects on the reaction rates induced by the organic groups should be the same as in $\mathbf{1}$, but the two alkoxide moieties are not tethered. No gelation occurred within 6 weeks. Only a small amount of a solid precipitate was formed after about $2 \mathrm{~h}$. Therefore, the gelation of $\mathbf{1}$ appears to be mainly a result of the tethering of the $\mathrm{Ti}(\mathrm{OR})_{3}$ and $\mathrm{Si}(\mathrm{OR})_{3}$ moieties; from the viewpoint of percolation theory, gelation of $\mathbf{1}$ should be easier than that of a mixture of $(\mathrm{acac}) \mathrm{Ti}\left(\mathrm{O}^{\mathrm{i}} \mathrm{Pr}\right)_{3}$ and $\mathrm{RSi}(\mathrm{OMe})_{3}$ because one link between the reacting species is preformed.

Both the precipitate and the supernatant solution were investigated by SAXS (Figure 1). Two peaks at 4 and 6.9 $\mathrm{nm}^{-1}(1: \sqrt{ } 3)$ were detected in the solid precipitate, indicating the existence of preformed particles with a distance of 1.5 $\mathrm{nm}$, from which a particle radius of approximately $0.75 \mathrm{~nm}$ is derived. The peaks are, however, very weak, which

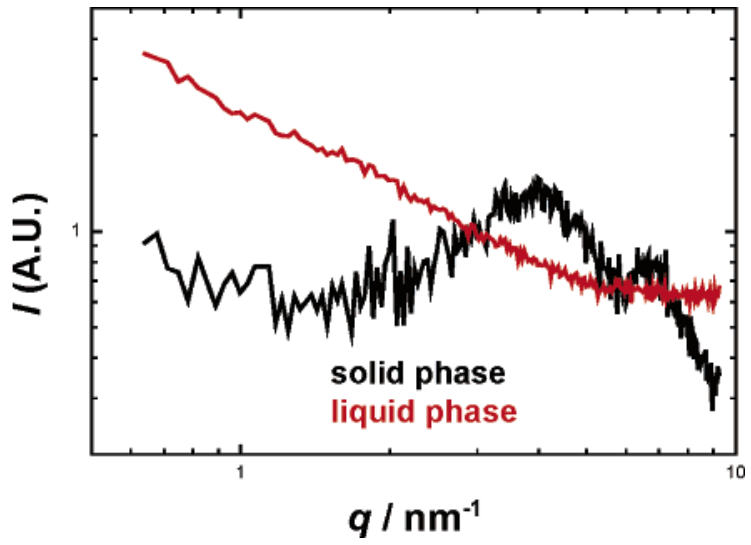

Figure 1. Scattering curves of the hydrolyzed $\mathrm{Ti}\left(\mathrm{O}^{i} \mathrm{Pr}\right)_{3}(\mathrm{acac}) / \mathrm{PrSi}(\mathrm{OMe})_{3}$ mixture after $7 \mathrm{~d}$. Red: supernatant liquid; black: precipitate. 


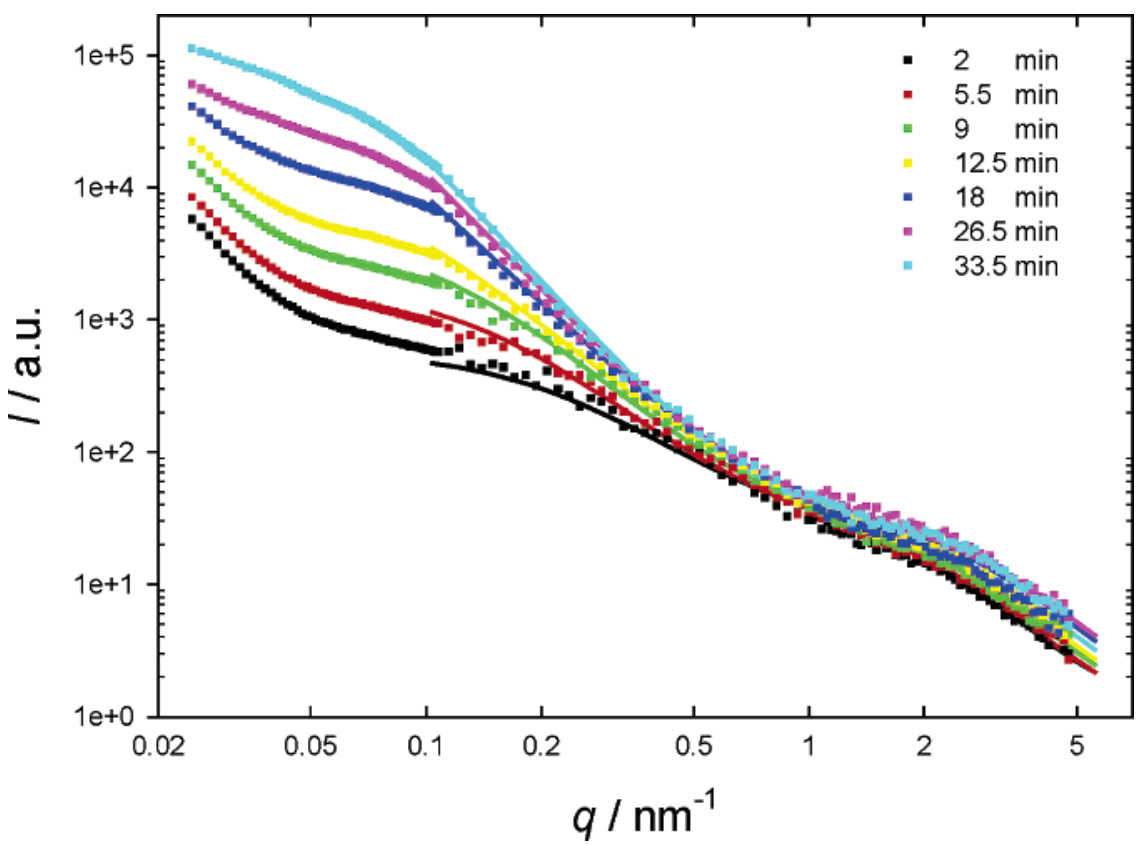

Figure 2. Scattering curves during the gelation of $\mathbf{1}$ (circles) together with the fitted curves (lines).

indicates that the proportion of ordered particles in the solution is small.

Gelation of $\mathbf{1}$. The gel time of $\mathbf{1}$ was $35 \mathrm{~min}$ for a water:1 ratio of 6 . The scattering curves of the gelling samples were recorded in regular intervals until the gel point was reached (Figure 2). From the very beginning of the reaction small primary particles were present as indicated by the shoulder in the high $q$-range. This feature of the SAXS curves does not change position and shape, but a slight increase in intensity was observed. This indicates that the size and shape of the primary particles remains constant once they are formed.

The background-corrected images were fitted with the adjustable parameters $A, B, D, r$, and $\xi$ according to eqs $2-4$. It turned out that the primary particle radius $r$ and the fractal dimension $D$ remained constant within the error of the fit at values of $r=0.5 \pm 0.2 \mathrm{~nm}$ and $D=2.5 \pm 0.1$ during the whole gelation process until the gel point. They were therefore set to these mean values to obtain a higher accuracy and a better convergence of the other parameters characterizing the aggregation process. Furthermore, it turned out that the parameter $A$ representing the primary particle volume did not increase considerably after the first $15 \mathrm{~min}$, indicating that the formation of the primary particles occurs mainly at the beginning of the reaction (Figure 3). Therefore, we focused on the parameters $B$ and $\xi$ characterizing the average number of primary particles in the aggregates and the aggregate size, respectively. Figure 4 shows the time dependence of the particle number $B$. The logarithmic scale (insert in Figure 4) reveals that there is a continuous and exponential increase of the number of primary particles in the aggregates.

The size of the aggregates is obtained by the cutoff distance $\xi$. Aggregation of the primary particles to secondary particles (clusters) already starts from the beginning. Both the number of primary particles in the cluster $(B)$ and their size $(\xi)$ increase exponentially with time, until their size

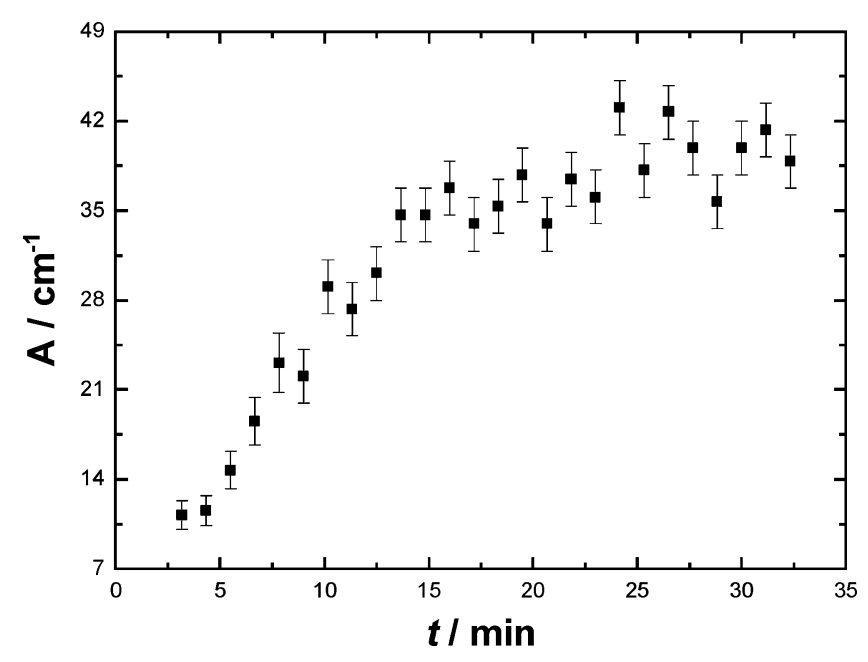

Figure 3. Time evolution of the parameter $A$ for Ti011 gels.

exceeds the measuring range (Figure 5). As was shown by eq 4 , and also seen in Figures 4 and $5, \log \mathrm{B}=$ const + $D \cdot \log \xi$. This leads to the conclusion that the aggregation process is not diffusion-, but instead reaction-limited.

Anomalous scattering (ASAXS) was measured at two different beam energies (4933 and $4983 \mathrm{eV}$ ) near the Ti K absorption edge to obtain information on the arrangement of the Ti atoms in the wet gel. The scattering curves were background- and fluorescence-corrected and the scattering intensity at the higher energy was subtracted from that at the lower energy. By this, the small-angle scattering specifically due to the Ti-related structures was separated (Figure 6).

Both scattering curves show identical behavior in the small $q$ range; i.e., the distribution of Ti reproduces the structure represented by the total scattering curve on a length scale $>15 \mathrm{~nm}$. At medium $q$ values $\left(0.3 \mathrm{~nm}^{-1}<q<0.8 \mathrm{~nm}^{-1}\right)$ the signal is very noisy due to experimental difficulties (in this region the covering polyethylene foil contributes significantly to the scattering), which diminishes the precision 


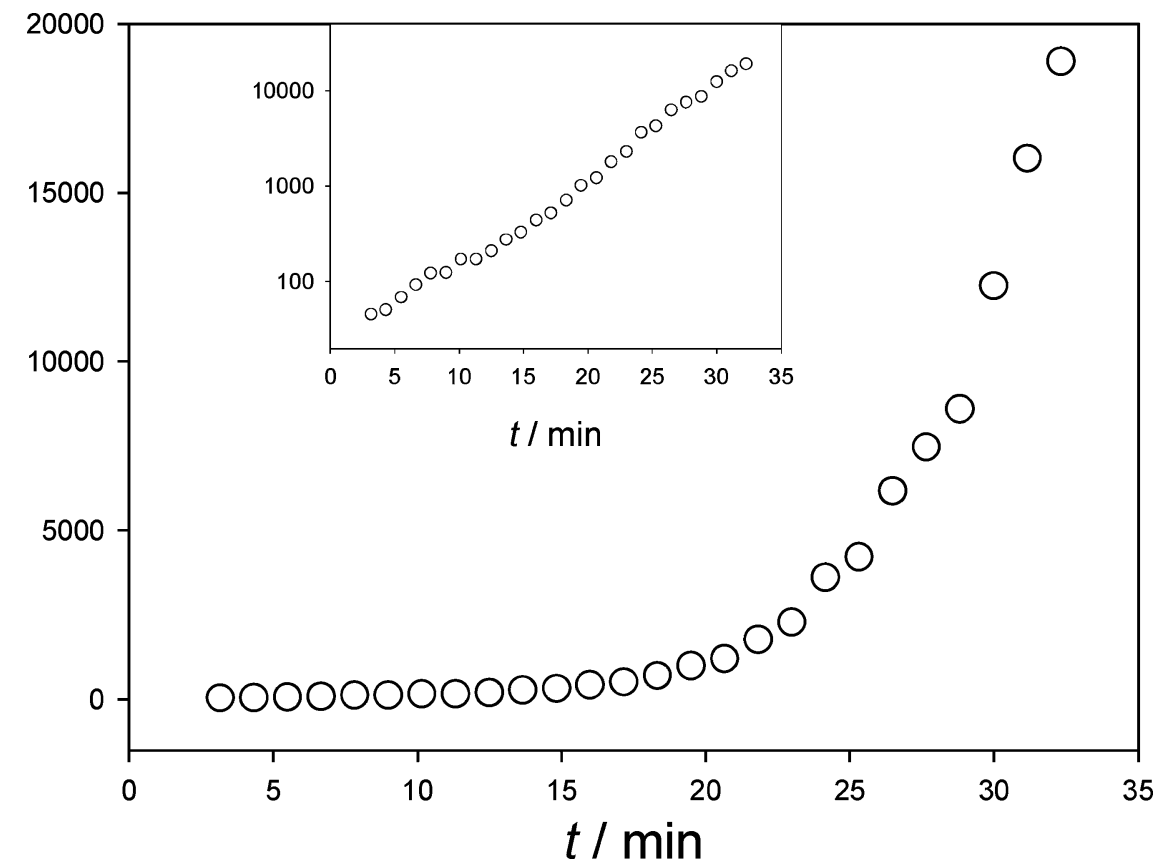

Figure 4. Time evolution of the number of particles in the aggregate $(B)$ for Ti011 gels. Insert: time evolution on a logarithmic scale.

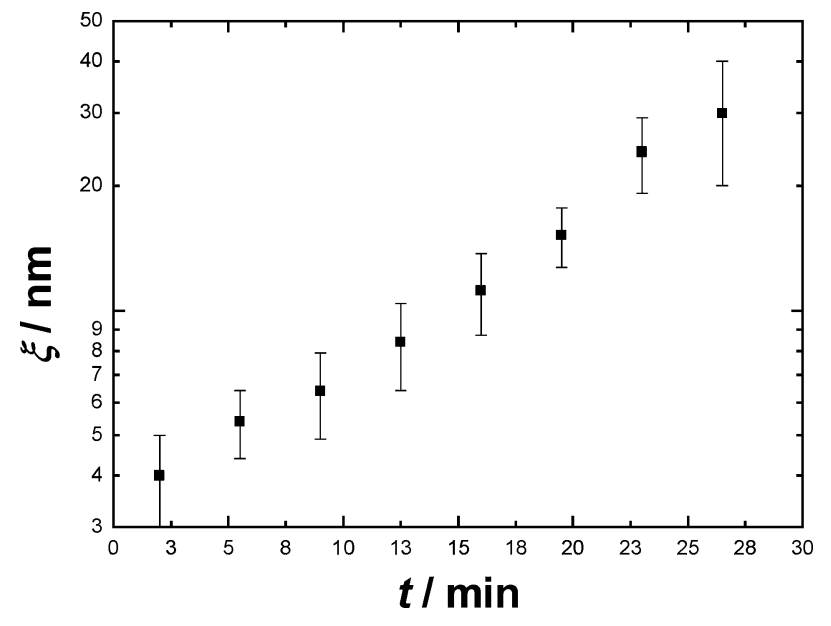

Figure 5. Size evolution of the secondary particles of Ti011 gels.

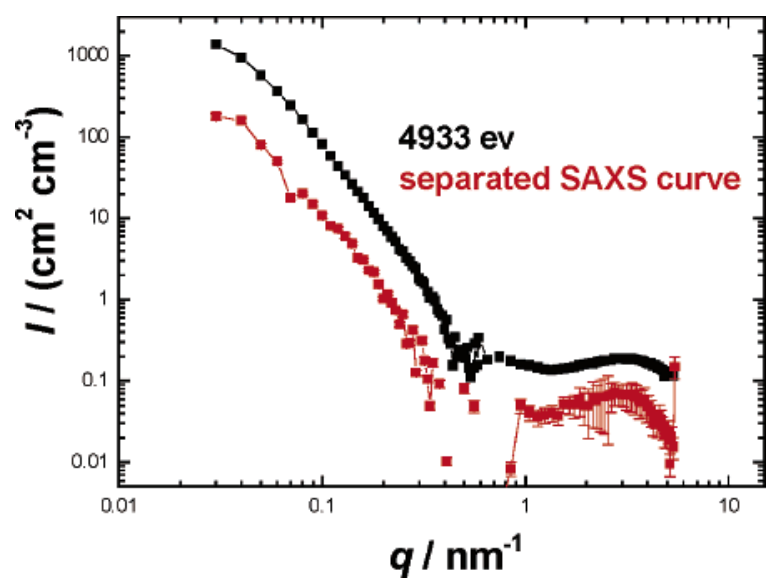

Figure 6. ASAXS measurements and the separated scattering curves of the wet gel Ti011. The separated scattering curve was obtained by subtraction of the measured SAXS curves at the higher energy from that at the lower energy.

of the background subtraction. Near a value of $q=3 \mathrm{~nm}^{-1}$ a broad peak is observed in the separated scattering curve, which also is an indication for a Ti-related periodically arranged structure with a typical distance of about $2 \mathrm{~nm}$ in real space.

Though the form factor of the $\mathrm{Ti}$ distribution cannot be determined by a measurement at only two energies, ${ }^{16}$ an interpretation of a periodically arranged Ti-rich core surrounded by a Si-rich shell appears to be consistent with the energy dependence of the total scattering curves and would be consistent with the higher reactivity of the $\mathrm{Ti}(\mathrm{OR})_{3}$ groups compared to $\mathrm{Si}(\mathrm{OR})_{3}$ groups.

Aging, Drying, and Calcination of Ti011. The wet Ti011 gel was aged at $30{ }^{\circ} \mathrm{C}$ for 7 days in closed bottles. SAXS measurements were made in regular intervals. The fractal dimension increased monotonically from 2.5 at the gel point to about 3 after 3 days of aging, and then remained constant. Equally, the size of the primary particles did not change within the experimental error. The size of the secondary particles $\xi$ was always higher than the experimentally accessible range of about $40 \mathrm{~nm}$.

After an aging period of 7 day, the Ti011 wet gel was dried at ambient conditions by removing the cover of the bottles and letting the solvent evaporate. The resulting xerogel Ti011x was still built from primary particles, but they were smaller $(r=0.4 \pm 0.1 \mathrm{~nm})$ than those in the wet gel. The size of the secondary particles decreased significantly upon drying: Whereas $\xi$ was outside the accessible range in the wet gels, it reduced to a value of $2.8 \pm 0.3 \mathrm{~nm}$ for Ti011x. The fractal dimension, however, was unchanged relative to that of the aged Ti011 gel.

Calcination of Ti011x resulted in the removal of the organic groups, especially the tether between the silicon and titanium atoms. In the resulting calcined xerogel Ti011xc, the primary particles were no longer observed (Figure 7). This kind of structure evolution was already found in the case of silica-zirconia gels. ${ }^{17}$ The new maximum at about $1.5 \mathrm{~nm}^{-1}$ after calcination could correspond to the onset of $\mathrm{TiO}_{2}$ particle formation; in high-temperature XRD experiments crystalline anatase particles of about $5 \mathrm{~nm}$ (i.e., the 


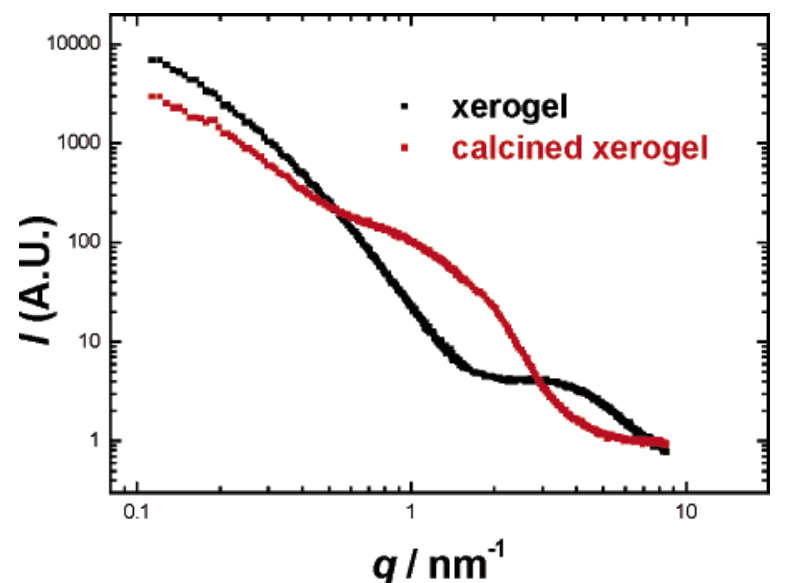

Figure 7. Scattering curves after drying (black curve) and calcination (red curve) of Ti011.

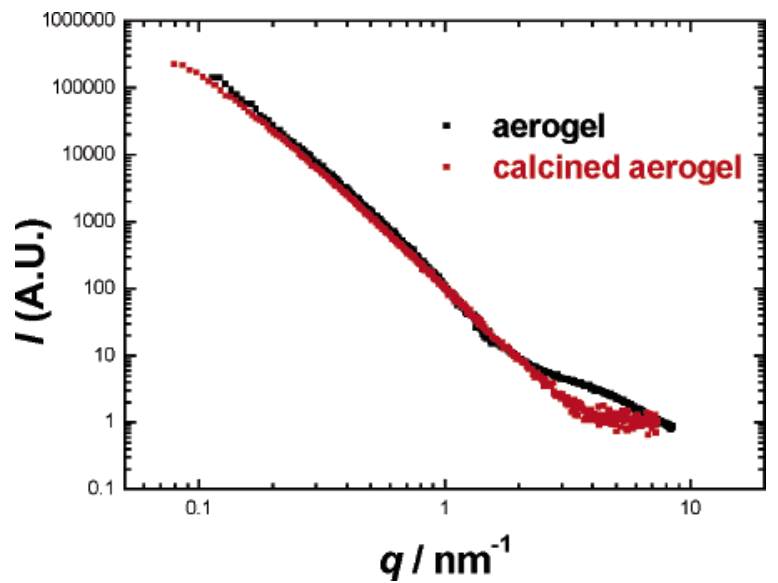

Figure 8. Scattering curves after supercritical drying (black curve) and calcination (red curve) of Ti011.

minimum size that allows detection by XRD) were observed at about $800{ }^{\circ} \mathrm{C} .{ }^{2}$

The results indicate that the appearance of the primary particles with radii of approximately $0.5 \mathrm{~nm}$ is closely connected to the presence of the organic link between the silicon and titanium atoms. The primary particles were observed through all stages of the gel preparation; they are formed immediately after the start of the hydrolysis reaction and retain their size $(r=0.5 \pm 0.1 \mathrm{~nm})$ until the drying stage, where a small decrease in size occurs $(r=0.4 \pm 0.1$ $\mathrm{nm})$. They only disappear once the organic groups are removed by calcination.

Aerogels from Ti011. Monolithic aerogels were obtained after supercritical drying with $\mathrm{CO}_{2}$. The aerogels Ti011a are less brittle than pure silica aerogels. The aerogels are also built from primary particles, which are smaller $(r=0.4 \pm$ $0.1 \mathrm{~nm}$ ) than that of the original wet gels, but comparable to the ones of xerogels. Contrary to the xerogels, the size of the secondary particles is much larger and outside the accessible measuring range (Figure 8). The fractal dimension was unchanged relative to the aged gels. Thus, the overall texture of the gel network was apparently not changed during supercritical drying. Similarly to the results on xerogels, the primary particles disappeared after calcination.

The calcination of Ti011a was followed in situ by SAXS (Figure 9). The reduction in the intensity of the scattering data, which is interpreted as a decomposition of the primary particles, occurred in two steps, viz. below and above 250 ${ }^{\circ} \mathrm{C}$ (insert in Figure 9); above $400{ }^{\circ} \mathrm{C}$ the primary particles were essentially absent. The disappearance of the primary particles is a consequence of the pyrolysis/thermolysis of the organic groups as discussed above.

The aerogel Ti011a was also investigated by ASAXS. The obtained background and fluorescence corrected SAXS curves at the two energies as well as the separated scattering curve are presented in Figure 10. A small broad peak was observed in the high- $q$ region of the separated SAXS curves. Compared to the wet gel Ti011, this peak was smaller and shifted to the higher $q$ values, i.e., the primary particles became smaller, as already observed before, but a nonstatistical distribution of $\mathrm{Ti}$ and $\mathrm{Si}$ atoms is still likely.

Gelation of 1/TEOS Mixtures. A structural model emerging from the SAXS measurements of Ti011 is the formation of small clusters (primary particles) by hydrolysis and condensation of the $\mathrm{Ti}\left(\mathrm{O}^{\mathrm{i}} \mathrm{Pr}\right)_{3}$ part of the precursor 1 . The clusters with a Ti/O core would be surrounded by $\mathrm{Si}(\mathrm{OMe})_{3}$ groups (linked to the cluster core by the organic groups), the hydrolysis and condensation of which is delayed. The addition of TEOS, i.e., another source of $\mathrm{Si} / \mathrm{O}$ units, raised the question in which part of the structure the extra $\mathrm{Si} / \mathrm{O}$ units would be incorporated. Under basic conditions, TEOS reacts faster than $\mathrm{RSi}(\mathrm{OMe})_{3},{ }^{18}$ and therefore there was a chance that the $\mathrm{Si} / \mathrm{O}$ units from TEOS would "dilute" the $\mathrm{Ti} / \mathrm{O}$ core of the primary particles. On the other hand, if the reaction of the $\mathrm{Ti}\left(\mathrm{O}^{i} \mathrm{Pr}\right)_{3}$ moieties would be faster than that of both TEOS and the $\mathrm{Si}(\mathrm{OMe})_{3}$ part of $\mathbf{1}$, the primary particle size would be unchanged, and $\mathrm{Si} / \mathrm{O}$ units would be incorporated into the $\mathrm{Si} / \mathrm{O}$ part of the overall structure.

When the 1:TEOS ratio was varied from 1:0 to $1: 1$ and $1: 2$, the gel time increased from 35 to 110 and $160 \mathrm{~min}$, respectively. The trend in the gelation times is contrary to what was previously observed for base-catalyzed $\mathrm{Si}(\mathrm{OR})_{4} /$ $\mathrm{R}^{\prime} \mathrm{Si}(\mathrm{OR})_{3}$ mixtures. However, it should be noted that the water:alkoxy group ratio was slightly decreased from 1.0 in Ti011 to 0.79 in Ti111 and 0.72 in Ti211.

The scattering curves of the gelling samples of Ti111 and Ti211 were recorded every $30 \mathrm{~s}$ until the gel point was reached (Figure 11). Immediately after water was added to the reaction mixture, small primary particles were present in all samples of this series with about the same diameter (about $0.5 \mathrm{~nm}$ ) as those in the Ti011 gel. In the high- $q$ area the shape and intensity of the SAXS curves remained constant during the whole gelation process, again indicating that the size of the primary particles did not change. The secondary particles, formed by aggregation of the primary particles, increased rapidly in size as the reaction proceeded and eventually became too big to be measurable (Figure 12). The intensity of the scattering curve increased rapidly concomitant with the increase in $\xi$.

An interesting difference between the Ti011 gel and the gels prepared by cohydrolysis of 1 and TEOS (Ti111 and Ti211) is that growth of the secondary particles in the latter samples was much slower, which parallels the increased gelation times. The parameter $B$ characterizing the number of particles per aggregate was, at the gel point, lower for 


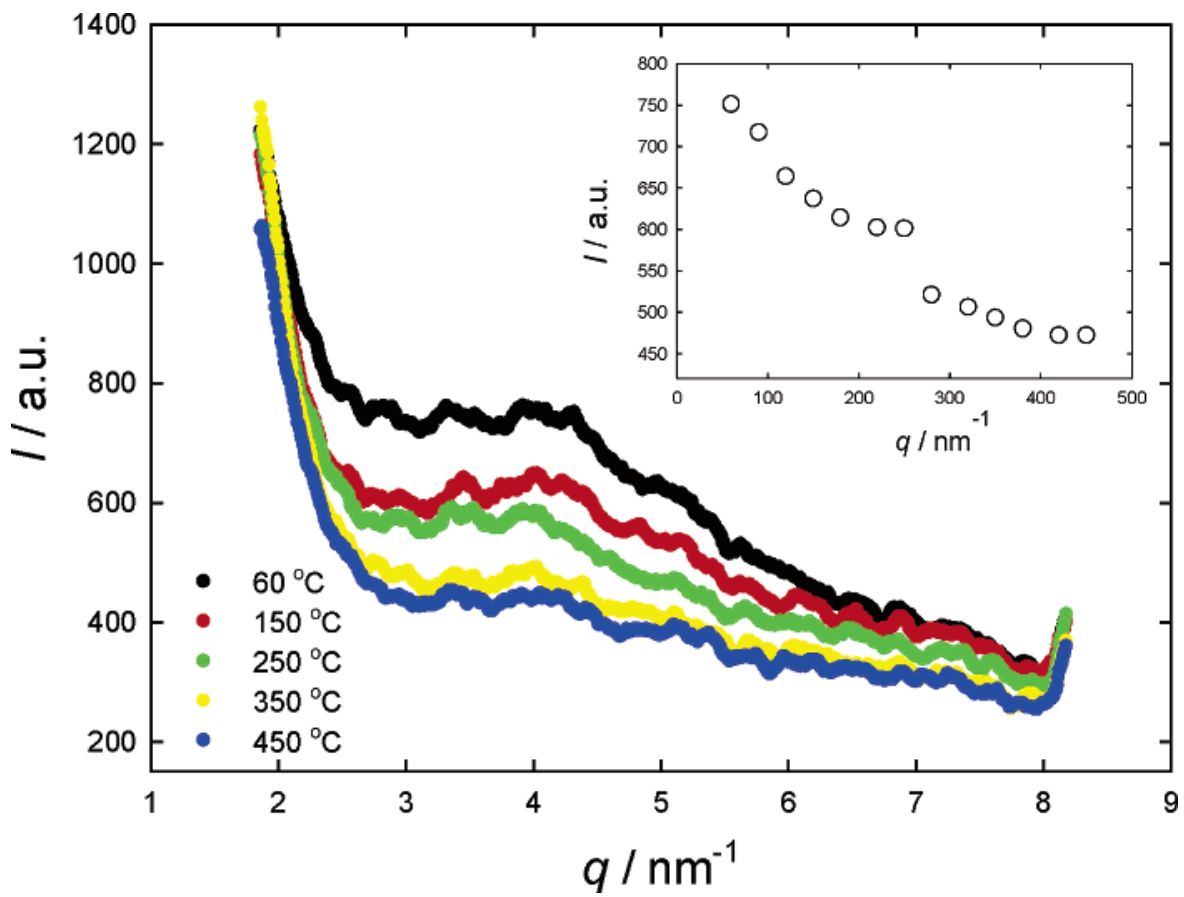

Figure 9. Structure evolution of Ti011a during calcination. The insert shows the intensity of the maximum at $q=4 \mathrm{~nm}^{-1}$ as a function of the temperature during the calcination of Ti011a.

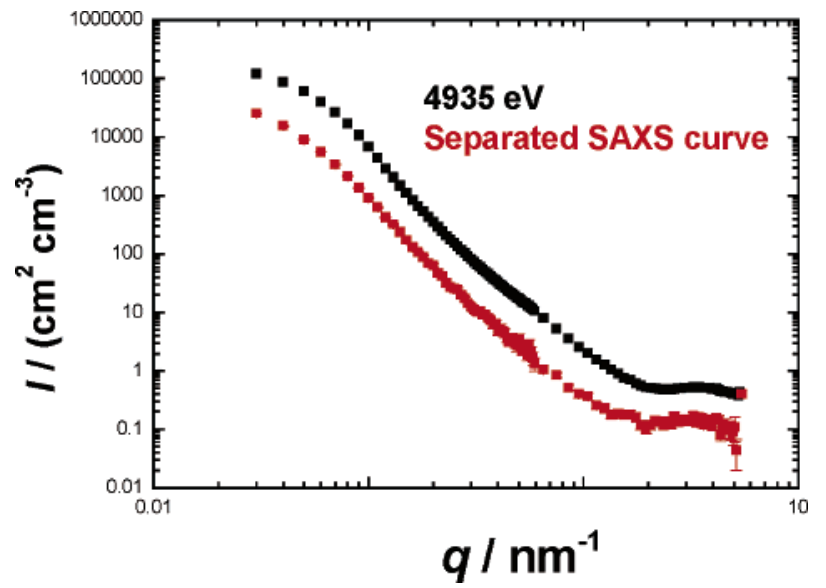

Figure 10. ASAXS measurements and the separated scattering curves of Ti011a. The separated scattering curve was obtained by subtraction of the measured SAXS curves at the higher energy from that at the lower energy.

Ti111 and Ti211 (26 and 21) than for Ti011 (40) and was approximately inversely proportional to the Si:Ti ratio. The lower concentration of primary particles per unit volume in Ti111 and Ti211 can be explained by the "dilution" of the samples by $\mathrm{SiO}_{2}$.

The fractal dimension of Ti111 $(1.9 \pm 0.1)$ and Ti211 $(2.0 \pm 0.1)$ at the gel point is slightly lower than that of Ti011; it increased to the same value (about 3 ) during aging for $3 \mathrm{~d}$.

\section{Discussion}

From the SAXS investigation the following picture on the structural evolution of the gel network evolves, when $\mathbf{1}$ is hydrolyzed alone or in the presence of TEOS. Immediately after the start of the reaction small primary particles are formed, the size of which $(r=0.5 \pm 0.1 \mathrm{~nm})$ remains constant through the gelation and aging process. This is similar to the HCl-catalyzed hydrolysis of pure $\mathrm{Ti}\left(\mathrm{O}^{\mathrm{i}} \mathrm{Pr}\right)_{4}$, where small primary particles of about the same size are also formed immediately after the start of the reaction. ${ }^{19}$ In the case of $\mathbf{1}$, nearly all primary particles are formed within the first $15 \mathrm{~min}$ of the reaction (see Figure 3), and the further formation rate is low. In combination with the ASAXS measurements, this is a strong indication that the primary particles are formed by hydrolysis and condensation of the $\mathrm{Ti}\left(\mathrm{O}^{\mathrm{i}} \mathrm{Pr}\right)_{3}$ moiety of $\mathbf{1}$. The clusters cannot grow to a large size because each titanium atom carries a $(\mathrm{OCMe})_{2} \mathrm{C}\left(\mathrm{CH}_{2}\right)_{3^{-}}$ $\mathrm{Si}(\mathrm{OMe})_{3}$ ligand and the organic groups cover the surface of the cluster. The size of the primary particles corresponds very well with that of known molecular titanium oxo clusters of 6-10 titanium atoms capped with organic ligands. ${ }^{20}$

Condensation proceeds by a slower aggregation of the primary particles, probably by the hydrolysis and condensation of the $\mathrm{Si}(\mathrm{OMe})_{3}$ groups. Additional $\mathrm{Si} / \mathrm{O}$ (from TEOS) is incorporated between the clusters; i.e., the additional $\mathrm{Si} / \mathrm{O}$ dilutes the clusters in the gel network. As the reaction proceeds, the size of the mass fractal secondary particles formed by aggregation of the primary particles increases approximately exponentially with the time; their radius is outside the measurable range when the gel point is reached. The fractal dimension of Ti011 at the gel point $(D=2.5)$ indicates that aggregation of the primary particles proceeds by a reaction-limited process (RLCA). ${ }^{21}$ When TEOS is added to the starting mixture, the fractal dimension becomes smaller $(D=1.9-2.0)$; i.e., more open fractal structures are formed. This could mean that the aggregation process becomes diffusion-limited (DLCA). The lower water:alkoxy

(19) Kamiyama, T.; Yoshida, N.; Suzuki, K. Bull. Inst. Chem. Res. 1994 $72,225$.

(20) Moraru, B.; Hüsing, N.; Kickelbick, G.; Schubert, U.; Fratzl, P.; Peterlik, H. Chem. Mater. 2002, 14, 2732.

(21) Brinker, C. J.; Scherer, G. W. Sol-Gel Science: The Physics and Chemistry of Sol-Gel Processing; Academic Press: Boston, 1990. 

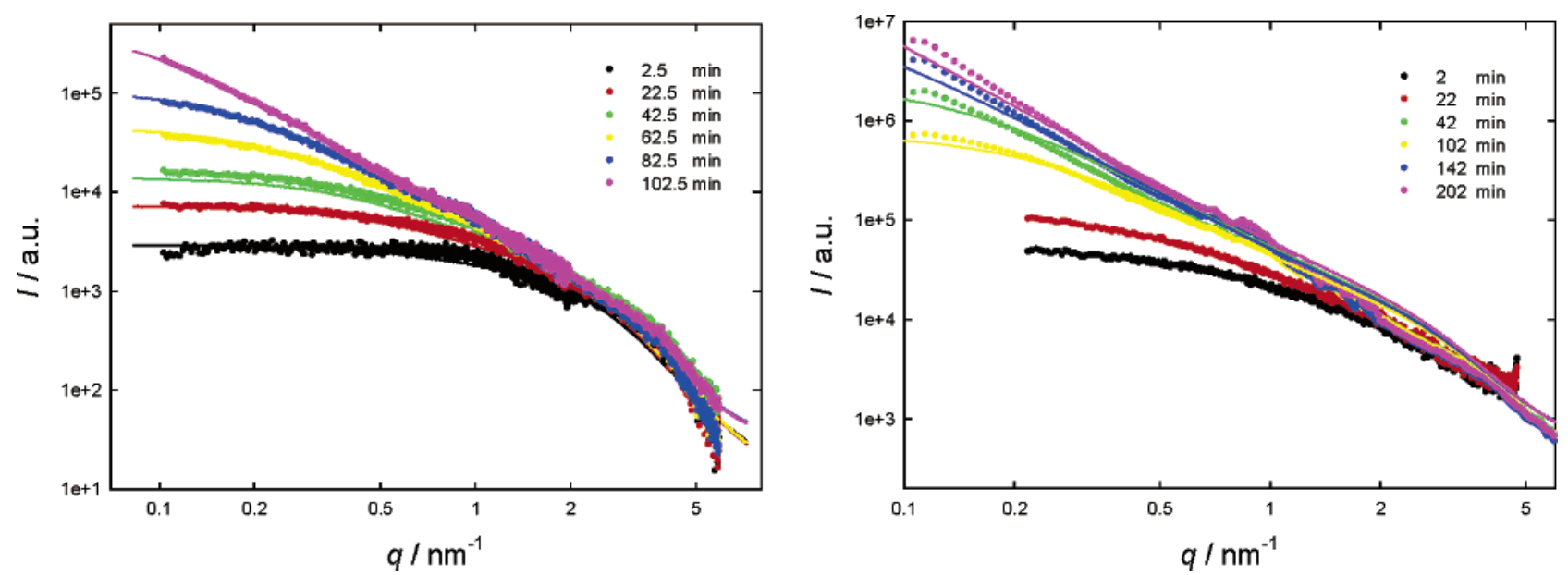

Figure 11. Scattering curves during the gelation of Ti111 (left) and Ti211 (right) together with the fits.
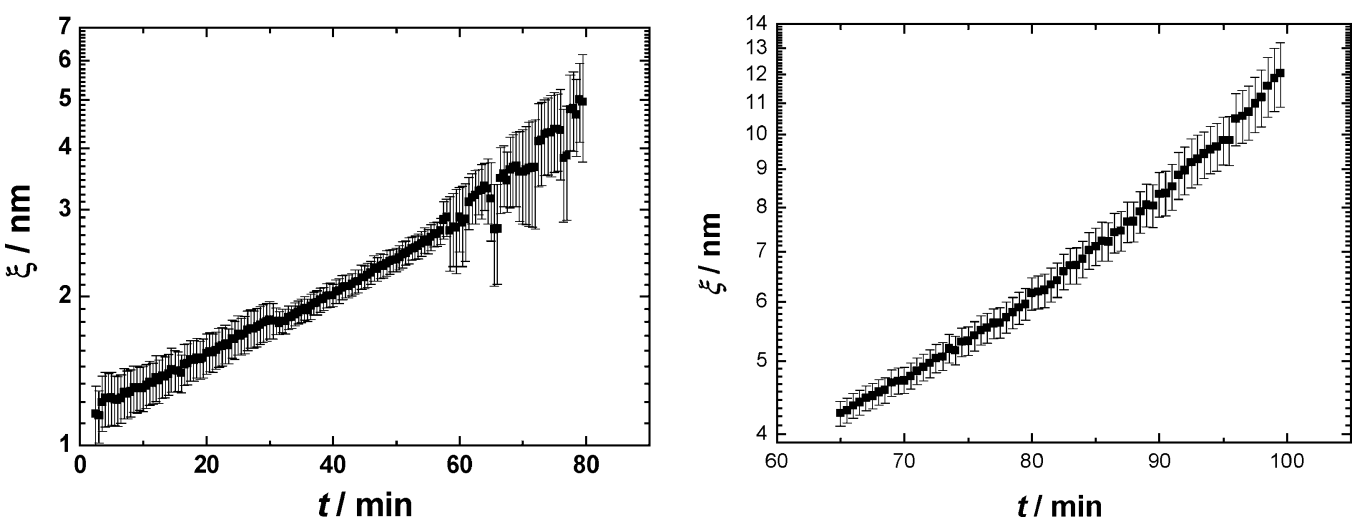

Figure 12. Size evolution of the secondary particles of Ti111(left) and Ti211(right).

group ratio in Ti111 and Ti211 could also play a role in lowering the fractal dimension. Similar fractal dimensions and primary particle sizes were observed for silica-titania gels prepared from TEOS and $\mathrm{Ti}(\mathrm{OR})_{4}$ under different conditions. ${ }^{16,22}$

Aging of the gels retains the general network structure of aggregated primary particles; only the fractal dimension increases to $D=3$ in all samples. This corresponds to the internal reorganization of the network and evolution of a dense structure.

Drying by either solvent evaporation or supercritical extraction with $\mathrm{CO}_{2}$ of Ti011 results in a decrease of the primary particle size to $r=0.4 \mathrm{~nm}$, probably caused by further condensation reactions within the Ti/O cluster core. The size of the secondary particles $\xi$ also decreases, probably for the same reason (which was the case for Ti111 and Ti211. For Ti011, $\xi$ is still outside the measurable range. However, it is assumed that this is due to the limitation of the experimental setup and it is suggested that there is a general decrease of $\xi$ during drying). The fractal dimension does not change during drying. These data imply that the general network structure is preserved and only some network contraction occurs.

During calcination in air, the organic groups tethering the silicon and titanium atoms are destroyed and replaced by

(22) De Lange, R. S. A.; Kumar, K.-N. P.; Hekkink, J. H. A.; Van De Velde, G. M. H.; Keizer, K.; Burggraaf, A. J.; Dokter, W. H.; Van Garderen, H. F.; Beelen, T. P. M. J. Sol-Gel Sci. Technol. 1994, 2, 489. oxo bridges. Since two of the coordination sites of the sixcoordinate titanium atoms are occupied by the $\beta$-diketone moiety prior to calcination, any Ti/O structure must undergo re-organization to maintain the six-coordination of the $\mathrm{Ti}$ atoms. Second, prior to calcination, the titanium and silicon atoms were separated by the organic tether. After calcination this is no longer the case. To accommodate both effects, major rearrangements in the vicinity of the original primary particles are necessary, which lead to their disappearance. However, the general structure of the network is maintained.

It must be pointed out at this point that this is a simplified model of what is occurring during the various stages of the preparation of xerogels and aerogels from 1 . The main reason for this is that a small proportion $(<15 \%)$ of $\mathrm{OTH}-\mathrm{H}$ is decomposed when reacted with $\operatorname{Ti}\left(\mathrm{O}^{i} \mathrm{Pr}\right)_{4} ;{ }^{3}$ the actual reaction mixture is more complex as discussed here (one of the decomposition products is the ketone $(\mathrm{MeO})_{3} \mathrm{Si}\left(\mathrm{CH}_{2}\right)_{4}$ $\mathrm{C}(\mathrm{O}) \mathrm{Me}$, which also participates in the sol-gel reactions). Nevertheless, the results presented in this work confirm our previous notion ${ }^{2}$ that the gels obtained from $\mathbf{1}$ are very homogeneous on a scale $>1 \mathrm{~nm}$. Only a nano-heterogeneity is observed due to the formation of Ti-rich primary particles.

Acknowledgment. This work was supported by the Fonds zur Förderung der wissenschaftlichen Forschung (FWF). We thank M. Kriechbaum for his help with the SAXS experiments and Dipl.-Ing. D.Hamann for building the extender of the sample holder.

CM047996N 